\title{
Differential Expression of Glu-Tubulin in Basal-Like Phenotype Carcinoma of the Mammary Gland
}

\author{
Hajime Kuroda $^{1 *}$, Yasuo Imai ${ }^{2}$, Kazuko Kuroso ${ }^{3}$, Masato Kojima ${ }^{3}$, Yoshihiko Ueda ${ }^{2}$ \\ ${ }^{1}$ Department of Pathology, International University of Health and Welfare Hospital, 537-3 Iguchi, \\ Nasushiobara, Japan \\ ${ }^{2}$ Department of Pathology, Dokkyo Medical University Koshigaya Hospital, Koshigaya, Japan \\ ${ }^{3}$ Departments of Surgery, Dokkyo Medical University Koshigaya Hospital, Koshigaya, Japan \\ Email: "hajimek@iuhw.ac.jp
}

Received April 5, 2013; revised May 8, 2013; accepted May 16, 2013

Copyright (c) 2013 Hajime Kuroda et al. This is an open access article distributed under the Creative Commons Attribution License, which permits unrestricted use, distribution, and reproduction in any medium, provided the original work is properly cited.

\begin{abstract}
High levels of tubulin expression have been described in a variety of human malignant tumors, and glu-tubulin, in which the C-terminal tyrosine of $\alpha$-tubulin is removed by tubulin carboxypeptidase. Over-expression has been reported in the malignant tumors of the mammary gland and correlated with poor prognosis immunohistochemically. Furthermore, Nielsen et al. proposed that the use of a panel of four markers (ER, HER 2, CK 5/6, and EGFR) could accurately identify basal-like phenotype carcinoma (BPC) with widely available standard pathologic tools. In our study, major prognostic factors such as patient age, tumor size, histological grade, axillary lymph node metastasis, vessel invasion, and local recurrence in BPC were not significantly different from non BP carcinoma (NBPC). However, the BPC group showed a higher ratio of distant metastasis than that of the NBPC group. In triple-negative carcinoma (TNC) cases, staining for glu-tubulin was observed in 46 cases (63.8\%), which consisted of 42 of the 58 BPC patients (72.4\%) and 4 of the 14 NBPC patients (28.6\%). A significant association was found between the expression of glu-tubulin and BPC, but not NBPC. It seems that our findings also agree with the observation that BPC exhibits aggressive biological behavior and increases the content of glu-tubulin, which plays a greater role in migration and invasion.
\end{abstract}

Keywords: Glu-Tubulin; Basal-Like Phenotype Carcinoma; Mammary Gland

\section{Introduction}

Microtubules, which consist of $\alpha \beta$-tubulin heterodimer, play a role in mitosis, cell motility, intracellular transport, and the maintenance of cell shape [1]. High levels of tubulin expression have been described in a variety of human malignant tumors, including ovary, colon, lung, prostate, and breast carcinomas [2-6]. Furthermore, glutubulin, in which the C-terminal tyrosine of $\alpha$-tubulin is removed by tubulin carboxypeptidase, overexpression has been reported in the malignant tumors of the mammary gland and correlated with poor prognosis immunohistochemically [7]. We previously showed that the majority of malignant tumors expressed the tubulin protein relative to benign tumors when breast tumor expression of glu-tubulin was evaluated immunohistochemically [8].

Histopathologic studies of triple-negative carcinoma (TNC) of the breast, which is characterized by a lack of estrogen receptor (ER) and progesterone receptor (PgR)

*Corresponding author. expression and the absence of HER 2 protein overexpression, indicated that these tumors, which are commonly treated with hormonal therapy and anti-HER 2 antibody (trastuzumab) therapy, are mostly unresponsive and typically have a poor prognosis [9]. Furthermore, Nielsen et al. suggested that the use of a panel of four markers such as ER, HER 2, CK 5/6, and epidermal growth factor receptor (EGFR) could accurately identify basal-like tumors with widely available standard pathologic tools [10]. They classified HER 2-positive tumors as an HER 2 subtype, ER-positive tumors as a luminal subtype, tumors with negative ER, negative HER 2, and positive CK 5/6 or positive EGFR as a basal-like phenotype carcinoma (BPC), and tumors that were negative for all these four markers as an undetermined subtype. This panel showed a high sensitivity and specificity for the identification of breast carcinomas with BPC and we also adopted these criteria in our definition of BPC. Several reports have shown that $\mathrm{BPC}$ is a poor prognostic factor in breast carcinoma [1113]. Thus, TNC can be classified into two subtypes: BPC 
and non-BPC (NBPC), and analyses should to be performed accordingly. As glutubulin is also present in the stable microtubules of malignant tumors with aggressive behavior, we speculated that glu-tubulin expression levels would differ between BPC and NBPC. In this study, we examined BPC in TNC patients and evaluated the biological behavior and impact of the glu-tubulin marker in immunohistochemical evaluations.

\section{Materials and Methods}

\section{Materials}

The patients included in this study were 554 patients with primary breast carcinoma who were treated at the Department of Pathology, Dokkyo Medical University Koshigaya Hospital between 2005 and 2011 for which paraffin blocks were available. For each case, all available hematoxylin and eosin-stained sections were reviewed to confirm the diagnosis of mammary disease by three observers who had no knowledge of either prior histological results or clinical outcomes and selected a representative block for immunostaining [14]. The sources, dilutions, and cutoff values of antibodies are listed in Table 1. Specimens were judged to be positive for ER or PgR when at least $1 \%$ of the tumor cells stained positively. HER2 was judged on the basis of a staining score range of 0 - 3 by the Hercep test, with a score of 0 or 1 rated as negative and a score of 2 or 3 as positive. Based on these results, 72 of the 554 patients (12.9\%) were judged to have triple negative carcinoma (TNC).

\section{Immunohistochemical Staining for Basal Marker (CK 5/6), Epidermal Growth Factor Receptor, and Glu-Tubulin}

CK 5/6 and EGFR were carried out to classify the 72 TNC cases as BPC or NBPC. Cases were considered CK $5 / 6$ and EGFR positive when at least $10 \%$ of the tumor cells showed membrane staining. TNC was judged to be BPC when the specimen was found to be positive for either CK 5/6 or EGFR. TNC found to be negative for

Table 1. Sources, dilutions, and cutoff values of the antibodies used in this study.

\begin{tabular}{|c|c|c|c|c|}
\hline Antibody & Clone & Manufacturer & Dilution & Cutoff values \\
\hline ER & SP1 & $\begin{array}{l}\text { Dako } \\
\text { Cytomation }\end{array}$ & Prediluted & $\begin{array}{l}\geqq 10 \% \\
\text { (positive) }\end{array}$ \\
\hline PgR & $1 \mathrm{E} 2$ & $\begin{array}{l}\text { Dako } \\
\text { Cytomation }\end{array}$ & Prediluted & $\begin{array}{l}\geqq 10 \% \\
\text { (positive) }\end{array}$ \\
\hline HER 2 & $4 \mathrm{~B} 5$ & $\begin{array}{l}\text { Dako } \\
\text { Cytomation }\end{array}$ & $\begin{array}{l}\text { Prediluted } \\
\text { (Hercep test) }\end{array}$ & $\begin{array}{l}0.1+ \\
\text { (negative) }\end{array}$ \\
\hline CK 5/6 & $\begin{array}{l}\text { D 5/16 } \\
\text { B4 }\end{array}$ & $\begin{array}{l}\text { Nichirei } \\
\text { Biosciences }\end{array}$ & Prediluted & $\begin{array}{l}\geqq 10 \% \\
\text { (positive) }\end{array}$ \\
\hline EGFR & $31 \mathrm{G} 7$ & $\begin{array}{l}\text { Nichirei } \\
\text { Biosciences }\end{array}$ & Prediluted & $\begin{array}{l}\geqq 10 \% \\
\text { (positive) }\end{array}$ \\
\hline glu-tubulin & polyclonal & $\begin{array}{l}\text { Cosmo } \\
\text { Bio }\end{array}$ & $1: 500$ & $\begin{array}{l}\geqq 10 \% \\
\text { (positive) }\end{array}$ \\
\hline
\end{tabular}

these markers was diagnosed as NBPC. Based on these markers, 58 of the 72 TNC patients were judged to be BPC and 14 were NBPC. Glu-tubulin was evaluated by immunohistochemical analysis using a specific antibody [15-18]. Five-micrometer-thick unstained sections were deparaffinized in xylene and rehydrated in a decreasing ethanol series (100\% - 50\%). After antigen retrieval with L.A.B. solution (Polyscience, Inc., Warrington, PA) for $20 \mathrm{~min}$ at $60^{\circ} \mathrm{C}$, endogenous peroxidase activity was quenched by exposure to $5 \% \mathrm{H}_{2} \mathrm{O}_{2}$ overnight at room temperature. Sections were then permeabilized with phosphate-buffered saline containing $0.5 \%$ Triton X-100 for 6 min. After washing twice with phosphate-buffered saline containing $0.3 \%$ Triton $\mathrm{X}-100$ for $10 \mathrm{~min}$, unspecific antibody binding was blocked with $1 \%$ goat serum for an hour. Sections were then incubated for 2 days at $4^{\circ} \mathrm{C}$ with a rabbit polyclonal anti-glu-tubulin antibody (Cosmo Bio, Tokyo, Japan) at 1:500 dilutions. After washing, sections were further processed with a Histofine SAB-PO(R) kit (Nichirei Corp., Tokyo, Japan) following the manufacturer's instructions. A color reaction was developed with 3, 3'-diaminobenzidine. After counterstaining with hematoxylin, sections were dehydrated, mounted with mountquick (Daido Sangyo Co. Ltd., Tokyo, Japan), and analyzed using an Olympus BX 51 microscope. Nerve fibers known to express high levels of glu-tubulin were used as positive controls and were included in each staining run. Cases were considered glutubulin-positive if cytoplasmic and/or membranous staining was observed in more than $10 \%$ of the cancer cells.

\section{Comparison of Clinicopathological Findings for BPC and NBPC}

Patients were classified as BPC or NBPC, and these two disease groups were compared in relation to the following clinicopathological parameters: age, tumor diameter, histological grade, lymph node status, vessel invasion status, local recurrence, distant metastasis, overall survival in months, and glu-tubulin overexpression.

\section{Statistical Methods}

All immunostains were initially reviewed and scored by 2 pathologists. A $\chi^{2}$ test was used to compute the statistical association and a $\mathrm{P}$ value of 0.05 was considered significant. The Kaplan-Meier method was used to calculate the overall survival in months and the survival rates. The log-rank test was used to test for significance, and a P-value of $<0.05$ was considered to indicate significance. Statistical analysis was carried out using Excel 2012 software.

\section{Results}

The histological and clinical characteristics of the BPC 
and NBPC cases identified in this study are summarized in Table 2. The ages of the 58 BPC cases, ranged from 28 to 87 years (mean, 57 years). The mean tumor size was $2.7 \mathrm{~cm}$ at the maximum diameter. The ages of the14 NBPC cases, ranged from 44 to 84 years (mean, 59 years). The mean tumor size was $2.4 \mathrm{~cm}$ at the maximum diameter. Major prognostic factors such as patient age, tumor size, histological grade, axillary lymph node metastasis, and vessel invasion were not significantly different between BPC and NBPC cases [14]. Local recurrence was found in 16 TNC patients, which consisted of 14 of the 58 BPC patients (24.1\%) and two of the NBPC patients (14.3\%). The incidence of local recurrence was higher in the BPC group than in the NBPC group, but this difference was not significant. In addition, the BPC group showed a significantly high ratio of visceral metastases, such as to the brain and lungs (Table 2). Complete follow-up data were available in 66 of the 72 patients diagnosed with TNCs. Of these patients, 11 died of the disease after the initial diagnosis of a primary lesion and 55 patients were alive 5 years after the initial diagnosis. These patients consisted of 9 patients from the BPC group and two patients from the NBPC group, but the difference was not significant.

In TNC cases, staining for glu-tubulin was observed in 46 cases (63.8\%) (Table 3), consisting of 42 of the 58 BPC patients (72.4\%) and 4 of the 14 NBPC patients (28.6\%). The staining pattern of breast carcinoma was predominantly characterized by the cytoplasmic staining of epithelial cells (Figure 1). In most tumors, some areas also showed cell-cell boundary staining. Only 26 cases showed no significant staining. A significant association

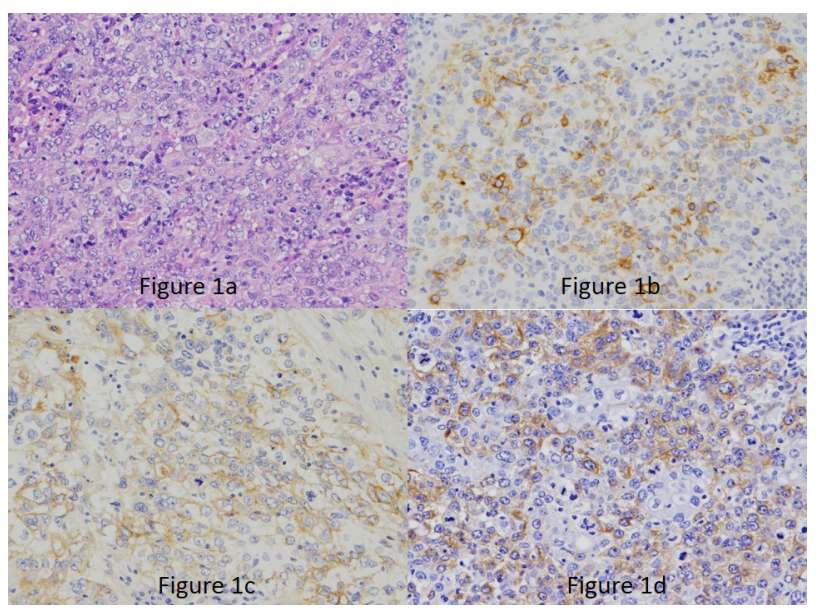

Figure 1. (a): Basal-like phenotype carcinoma (BPC) showing a high-grade invasive ductal carcinoma not otherwise specified, composed of sheets of marked pleomorphism (H\&E 200×); (b): Cytokeratin 5/6 (200×); (c): EGFR (200×); (d): carcinoma with strong and diffuse cytoplasmic reactivity of tumor cells to the glu-tubulin antibody scored as positive $(200 \times)$.
Table 2. The relationship between histological carcinoma characteristics.

\begin{tabular}{|c|c|c|c|c|}
\hline & TNC (72) & BP (58) & NBP (14) & $\mathrm{P}$ value \\
\hline \multicolumn{5}{|l|}{ Age } \\
\hline mean & 58 & 57 & 59 & \multirow{3}{*}{0.9858} \\
\hline$\leqq 50$ & 23 & 19 & 4 & \\
\hline$>50$ & 49 & 39 & 10 & \\
\hline \multicolumn{5}{|l|}{ Tumor size } \\
\hline mean & 2.6 & 2.7 & 2.4 & \multirow{3}{*}{0.3972} \\
\hline$\leqq 2$ & 33 & 28 & 5 & \\
\hline$>2$ & 39 & 30 & 9 & \\
\hline \multicolumn{5}{|l|}{ Histological grade } \\
\hline I & 2 & 1 & 1 & \multirow{3}{*}{0.3432} \\
\hline II & 6 & 4 & 2 & \\
\hline III & 64 & 53 & 11 & \\
\hline \multicolumn{5}{|l|}{ Lymph node status } \\
\hline Negative & 38 & 30 & 8 & \multirow{2}{*}{0.7155} \\
\hline Positive & 34 & 28 & 6 & \\
\hline \multicolumn{5}{|l|}{ Vessel invasion } \\
\hline Negative & 39 & 32 & 7 & \multirow{2}{*}{0.7274} \\
\hline Positive & 33 & 26 & 7 & \\
\hline \multicolumn{5}{|l|}{ Local recurrence } \\
\hline Negative & 56 & 44 & 12 & \multirow{2}{*}{0.6616} \\
\hline Positive & 16 & 14 & 2 & \\
\hline \multicolumn{5}{|l|}{ Distant metastasis } \\
\hline Brain & 3 & 3 & 0 & \multirow{5}{*}{0.0405} \\
\hline Lung & 4 & 4 & 0 & \\
\hline Liver & 1 & 1 & 0 & \\
\hline Bone & 3 & 3 & 0 & \\
\hline $\begin{array}{l}\text { Other lymph node } \\
\text { group }\end{array}$ & 3 & 3 & 0 & \\
\hline
\end{tabular}

Table 3. Relationship between glu-tubulin expression and intrinsic subtypes.

\begin{tabular}{ccccc}
\hline \multirow{2}{*}{ Glu-tubulin } & BP & NBP & P value \\
& negative & 16 & 10 & \multirow{2}{*}{0.0006} \\
& positive & 42 & 4 & \\
\hline
\end{tabular}

BP: Basal-like Phenotype NBP: Non-Basal-like Phenotype.

was found between the expression of glu-tubulin and BPC, but not NBPC.

\section{Discussion}

Recent studies using cDNA microarray technology and unsupervised cluster analysis have provided new insights into the classification of invasive breast cancers. These studies have resulted in the identification of several breast cancer subgroups that differ in their gene expression signatures and clinical course [19-22]. The majority of BPs lack ER, PgR, and HER 2 expression, and several 
reports have adopted a TNC definition for BPCs, an approach that is convenient in routine practice. However, it should be noted that an overlap between TNC and BPC exists and gene expression cannot be applied to clinically available formalin fixed, paraffin-embedded tissues. This method is relatively expensive and has not been established in routine management. On the basis of the above reason, a convenient method to identify these BPCs in pathological specimens would involve certain markers for immunohistochemical analysis. Several immunohistochemical analysis surrogates have been proposed for the routine identification of BPC. Nielsen et al. proposed an immunohistochemical analysis surrogate based on four markers (ER, HER 2, CK 5/6, and EGFR) and we arranged and adopted these criteria for the definition of BPC [10]. As a result, in our study, among the 72 cases of TNCs, 58 cases completely overexpressed CK 5/6 or EGFR and had a possible classification of BPC, which was true for as the majority of TNCs based on the simple analysis of ER, PR, and HER 2 [23]. Major prognostic factors such as patient age, tumor size, axillary lymph node metastasis, vessel invasion, and local recurrence were not significant. Furthermore, there were no significant differences in the histological grade corresponding to tubule formation, nuclear pleomorphism, and mitotic counts. However, for our present patient series, distant metastasis was clearly significant in BPC patients. This result indicates that BPC has a different biological behavior from NBPC with no clear morphologic features.

A preliminary limited survey of previous reports indicated the differential expression of tubulin in several types of carcinomas [2-7]. Moreover, in human breast cancers, the accumulation of glu-tubulin has been correlated with poor prognosis using an immunohistochemical approach [7]. In this report, we evaluated the glu-tubulin expression of a large number of breast cancer cases to examine the hypothesis that glu-tubulin expression may be significantly different between BPC and NBPC. Numerous studies have investigated microtubules in cell migration, and a form of stabilized tubulin was shown to accumulate in the microtubules of migrating cells [24-26]. Stable microtubules such as glu-tubulin increase cell migration because they act as a directed membrane and are involved in cell-organ transportation of the cell, regulating adhesion and contraction $[27,28]$. In previous reports, BPC demonstrated a specific pattern of distant metastasis with a high ratio of visceral metastases, such as to the brain and lung [29,30]. The mechanism leading to this result is still unclear. However, BPC has a higher ratio of distant metastasis than NBPC and it seems that those findings are compatible with the observation of increases in the content of glu-tubulin, which plays a role in migration and invasion.

In summary, we reported glu-tubulin expression in a series of invasive breast carcinomas of distinct subclasses such as BPC and NBPC based on immunohistochemical staining. Considering the fact that biological behavior and glu-tubulin expression is obviously different between BPC and NBPC, may need to be established different pathological and clinical strategies for TNC patients.

\section{Acknowledgements}

We thank Kazunori Fukuda, Shinya Wakamatsu, Kazuaki Hachimura, Satoko Souma, and Shinichi Kamikura for their technical assistance.

\section{REFERENCES}

[1] O. C. Rodriguez, A. W. Schaefer, C. A. Mandato, P. Forscher, W. M. Bement and C. M. Waterman-Storer, "Conserved Microtubule-Actin Interactions in Cell Movement and Morphogenesis," Nature Cell Biology, Vol. 5, No. 7, 2003, pp. 599-609. doi:10.1038/ncb0703-599

[2] M. Kavallaris, D. Y. Kuo, C. A. Burkhart, D. L. Regl, M. D. Norris, M. Haber and S. B. Horwitz, "Taxol-Resistant Epithelial Ovarian Tumors Are Associated with Altered Expression of Specific Beta-Tubulin Isotypes," Journal of Clinical Investigation, Vol. 100, No. 5, 1997, pp. 12821293. doi:10.1172/JCI119642

[3] G. Carles, D. Braguer, C. Dumontet, V. Bourgarel, A. Gonçalves, M. Sarrazin, J. B. Rognoni and C. Briand, "Differentiation of Human Colon Cancer Cells Changes the Expression of Beta-Tubulinisotypes and MAPs," British Journal of Cancer, Vol. 80, No. 8, 1999, pp. 11621168. doi:10.1038/sj.bjc.6690481

[4] P. Sève, S. Isaac, O. Trédan, P. J. Souquet, Y. Pachéco, M. Pérol, L. Lafanéchère, A. Penet, E. L. Peiller and C. Dumontet, "Expression of Class III $\beta$-Tubulin Is Predictive of Patient Outcome in Patients with Non-Small Cell Lung Cancer Receiving Vinorelbine-Based Chemotherapy,” Clinical Cancer Research, Vol. 11, No. 15, 2005, pp. 5481-5486. doi:10.1158/1078-0432.CCR-05-0285

[5] S. Terry, G. Ploussard, Y. Allory, N. Nicolaiew, F. Boissière-Michot, P. Maillé, L. Kheuang, E. Coppolani, A. Ali, F. Bibeau, S. Culine, R. Buttyan, A. de la Taille and F. Vacherot, "Increased Expression of Class III Beta-Tubulin in Castration-Resistant Human Prostate Cancer," British Journal of Cancer, Vol. 101, No. 6, 2009, pp. 951-956. doi:10.1038/sj.bjc.6605245

[6] C. Bernard-Marty, I. Treilleux, C. Dumontet, F. Cardoso, A. Fellous, D. Gancberg, M. C. Bissery, M. Paesmans, D. Larsimont, M. J. Piccart and A. Di Leo, "MicrotubuleAssociated Parameters as Predictive Markers of Docetaxel Activity in Advanced Breast Cancer Patients: Results of a Pilot Study," Clinical Breast Cancer, Vol. 3, No. 5, 2002, pp. 341-345. doi:10.3816/CBC.2002.n.037

[7] A. Mialhe, L. Lafanechère, I. Treilleux, N. Peloux, C. Dumontet, A. Brémond, M. H. Panh, R. Payan, J. Wehland, R. L. Margolis and D. Job, “Tubulin Detyrosination Is a Frequent Occurrence in Breast Cancers of Poor Prognosis,” Cancer Research, Vol. 61, No. 13, 2001, pp. 50245027. 
[8] H. Kuroda, K. Saito, M. Kuroda and Y. Suzuki, "Differential Expression of Glu-Tubulin in Relation to Mammary Gland Disease,” Virchows Archives, Vol. 457, No. 4, 2010, pp. 477-482. doi:10.1007/s00428-010-0955-Z

[9] S. Cleator, W. Heller and R. C. Coombes, "Triple-Negative Breast Cancer: Therapeutic Options," Lancet Oncology, Vol. 8, No. 3, 2007, pp. 235-244. doi:10.1016/S1470-2045(07)70074-8

[10] T. O. Nielsen, F. D. Hsu, K. Jensen, M. Cheang, G. Karaca, Z. Hu, T. Hernandez-Boussard, C. Livasy, D. Cowan, L. Dressler, L. A. Akslen, J. Ragaz, A. M. Gown, C. B. Gilks, M. van de Rijn and C. M. Perou, "Immunohistochemical and Clinical Characterization of the Basal-Like Subtype of Invasive Breast Carcinoma," Clinical Cancer Research, Vol. 10, No. 16, 2004, pp. 5367-5374. doi:10.1158/1078-0432.CCR-04-0220

[11] E. A. Rakha, M. E. El-Sayed, A. R. Green, A. H. Lee, J. F. Robertson and I. O. Ellis, "Prognostic Markers in TripleNegative Breast Cancer,” Cancer, Vol. 109, No. 1, 2007, pp. 25-32. doi:10.1002/cncr.22381

[12] K. P. Siziopkou and M. Cobleigh, “The Basal Subtype of Breast Carcinomas May Represent the Group of Breast Tumors That Could Benefit from EGFR-Targeted Therapies,” Breast, Vol. 16, No. 1, 2007, pp. 104-107. doi:10.1016/j.breast.2006.09.003

[13] M. Sasa, Y. Bando, M. Takahashi, T. Hirose and T. Nagao, "Screening for Basal Marker Expression Is Necessary for Decision of Therapeutic Strategy for Triple-Negative Breast Cancer,” Journal of Surgical Oncology, Vol. 97, No. 1, 2008, pp. 30-34. doi:10.1002/jso.20906

[14] C. W. Elston and I. O. Ellis, "Pathological Prognostic Factors in Breast Cancer. I. The Value of Histological Grade in Breast Cancer: Experience from a Large Study with Long-Term Follow-Up,” Histopathology, Vo1. 19, No. 5, 1991, pp. 403-410.

[15] G. G. Gundersen and J. C. Bulinski, "Microtubule Arrays in Differentiated Cells Contain Elevated Levels of a PostTranslationally Modified Form of Tubulin," European Journal of Cell Biology, Vol. 42, No. 2, 1986, pp. 288294.

[16] T. E. Kreis, "Microtubules Containing Detyrosinated Tubulin Are Less Dynamic,” EMBO Journal, Vol. 6, No. 9, 1987, pp. 2597-2606.

[17] E. Schulze, D. J. Asai, J. C. Bulinski and M. Kirschner, "Posttranslational Modification and Microtubule Stability,” Journal of Cell Biology, Vol. 105, No. 5, 1987, pp. 2167-2177. doi:10.1083/jcb.105.5.2167

[18] A. R. Prescott, M. Vestberg and R. M. Warn, "Microtubules Rich in Modified Alpha-Tubulin Characterize the Tail Processes of Motile Fibroblasts," Journal of Cell Science, Vol. 94, No. 2, 1989, pp. 227-236.

[19] C. M. Perou, T. Sørlie, M. B. Eisen, M. van de Rijn, S. S. Jeffrey, C. A. Rees, J. R. Pollack, D. T. Ross, H. Johnsen, L. A. Akslen, O. Fluge, A. Pergamenschikov, C. Williams, S. X. Zhu, P. E. Lønning, A. L. Børresen-Dale, P. O. Brown and D. Botstein, "Molecular Portraits of Human Breast Tumours,” Nature, Vol. 406, No. 6797, 2000, pp. 747752. doi:10.1038/35021093

[20] T. Sørlie, C. M. Perou, R. Tibshirani, T. Aas, S. Geisler,
H. Johnsen, T. Hastie, M. B. Eisen, M. van de Rijn, S. S. Jeffrey, T. Thorsen, H. Quist, J. C. Matese, P. O. Brown, D. Botstein, P. E. Lønning and A. L. Børresen-Dale, "Gene Expression Patterns of Breast Carcinomas Distinguish Tumor Subclasses with Clinical Implications," Proceedings of National Academy Science of the USA, Vol. 98, No. 19, 2001, pp. 10869-10874.

doi:10.1073/pnas.191367098

[21] T. Sorlie, R. Tibshirani, J. Parker, T. Hastie, J. S. Marron, A. Nobel, S. Deng, H. Johnsen, R. Pesich, S. Geisler, J. Demeter, C. M. Perou, P. E. Lønning, P. O. Brown, A. L. Børresen-Dale and D. Botstein, "Repeated Observation of Breast Tumor Subtypes in Independent Gene Expression Data Sets," Proceedings of National Academy Science of the USA, Vol. 100, No. 14, 2003, pp. 8418-8423. doi:10.1073/pnas.0932692100

[22] J. D. Brenton, L. A. Carey, A. A. Ahmed and C. Caldas, "Molecular Classification and Molecular Forecasting of Breast Cancer: Ready for Clinical Application?” Journal of Clinical Oncology, Vol. 23, No. 29, 2005, pp. 73507360. doi:10.1200/JCO.2005.03.3845

[23] B. G. Haffty, Q. Yang, M. Reiss, T. Kearney, S. A. Higgins, J. Weidhaas, L. Harris, W. Hait and D. Toppmeyer, "Locoregional Relapse and Distant Metastasis in Conservatively Managed Triple Negative Early-Stage Breast Cancer,” Journal of Clinical Oncology, Vol. 24, No. 36, 2006, pp. 5652-5657.

[24] T. Wittmann and C. M. Waterman-Storer, "Cell Motility: Can Rho GTPases and Microtubules Point the Way?” Journal of Cell Science, Vol. 114, No. 21, 2001, pp. 3795-3803.

[25] I. R. Nabi, “The Polarization of the Motile Cell,” Journal of Cell Science, Vol. 112, No. 12, 1999, pp. 1803-1811.

[26] Y. Zheng, "G Protein Control of Microtubule Assembly," Annual Reviews Cell and Developmental Biology, Vol. 20, 2004, pp. 867-894. doi:10.1146/annurev.cellbio.20.012103.094648

[27] G. G. Gundersen and J. C. Bulinski, "Selective Stabilization of Microtubules Oriented toward the Direction of Cell Migration,” Proceedings of National Academy Science of the USA, Vol. 85, No. 16, 1988, pp. 5946-5950. doi:10.1073/pnas.85.16.5946

[28] Y. Wen, C. H. Eng, J. Schmoranzer, N. Cabrera-Poch, E. J. Morris, M. Chen, B. J. Wallar, A. S. Alberts and G. G. Gundersen, "EB1 and APC Bind to mDia to Stabilize Microtubules Downstream of Rho and Promote Cell Migration,” Nature Cell Biology, Vol. 6, No. 9, 2004, pp. 820830. doi:10.1038/ncb1160

[29] D. G. Hicks, S. M. Short, N. L. Prescott, S. M. Tarr, K. A. Coleman, B. J. Yoder, J. P. Crowe, T. K. Choueiri, A. E. Dawson, G. T. Budd, R. R. Tubbs, G. Casey and R. J. Weil, "Breast Cancers with Brain Metastases Are More Likely to Be Estrogen Receptor Negative, Express the Basal Cytokeratin CK5/6, and Overexpress HER2 or EGFR,” American Journal of Surgical Pathology, Vol. 30, No. 19, 2006, pp. 1097-1104. doi:10.1097/01.pas.0000213306.05811.b9

[30] H. Tsuda, T. Takarabe, F. Hasegawa, T. Fukutomi and S. Hirohashi, "Large, Central Acellular Zones Indicating My- 
oepithelial Tumor Differentiation in High-Grade Invasive Ductal Carcinomas as Markers of Predisposition to Lung and Brain Metastases,” American Journal of Surgical
Pathology, Vol. 24, No. 2, 2000, pp. 197-202. doi:10.1097/00000478-200002000-00005 